\title{
Transcriptomic Profile of Distal Middle Cerebral Artery from Moyamoya Disease Patients Reveals a Potential Unique Pathway
}

\author{
Yulius Hermanto ${ }^{1,2}$, Kent Doi ${ }^{1}$, Ahmad Faried ${ }^{2}$, Achmad Adam $^{2}$, Tondi M Tjili ${ }^{3}$, Muhammad Z. Arifin ${ }^{2}$, Yasushi Takagi ${ }^{4 *}$, \\ Susumu Miyamoto \\ ${ }^{1}$ Department of Neurosurgery, Graduate School of Medicine, Kyoto University, Kyoto, Japan; ${ }^{2}$ Department of Neurosurgery, \\ Faculty of Medicine, Universitas Padjadjaran, Bandung, Indonesia; ${ }^{3}$ Neurosurgery Division, Department of Surgery, Faculty of \\ Medicine, Riau University, Pekanbaru, Indonesia; ${ }^{4}$ Department of Neurosurgery, Institute for Biological Sciences, Tokushima \\ University, Tokushima, Japan
}

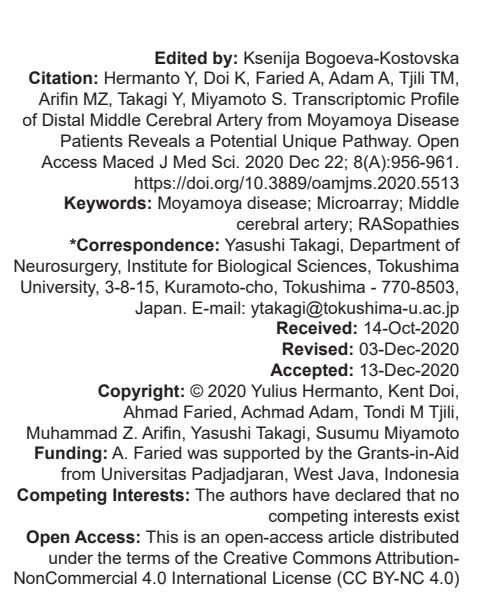

\begin{abstract}
BACKGROUND: Moyamoya disease (MMD) is a peculiar disease, characterized by progressive steno-occlusion of the distal ends of bilateral internal carotid arteries and their proximal branches. Numerous studies of MMD investigated as a singular pathway, thus overlooked the complexity of MMD pathobiology.

AIM: In this study, we sought to investigate the gene expression in the involved arteries to reveal the nove mechanism of MMD.

MATERIALS AND METHODS: Eight middle cerebral artery (MCA) specimens were obtained from six patients underwent surgical procedure superficial temporal artery to MCA (STA-MCA bypass) for MMD and two contro patients. We performed RNA extraction and microarray analysis with Agilent Whole Human Genome DNA microarray 4x44K ver.2.0 (Agilent Tech., Inc., Wilmington, DE, USA)

RESULTS: From 42,405 gene probes assayed, 921 gene probes were differentially regulated in MCA of patients with MMD. Subsequent pathway analysis with PANTHER database revealed that angiogenesis, inflammation, integrin, platelet-derived growth factor (PDGF), and WNT pathways were distinctly regulated in MMD. Among genes in aforementioned pathways, SOS1 and AKT2 were the mostly distinctly regulated genes and closely associated with RAS pathway.

CONCLUSION: The gene expression in MCA of patients with MMD was distinctly regulated in comparison with control MCA; presumably be useful for elucidating MMD pathobiology.
\end{abstract}

\section{Introduction}

Moyamoya disease (MMD) is a peculiar disease, characterized by progressive steno-occlusion of the distal ends of bilateral internal carotid arteries (ICAs) and their proal vascular network at the base of the brain (moyamoya vessels) is formed as a result of progressive ischemic changes in the brain [1], [2], [3]. The high incidence of MMD in Japanese population and high proportion of familial cases suggest the involvement of a genetic factor, particularly polymorphism in RNF213 gene [4], [5], [6].

Pathological evaluations on autopsy subjects have demonstrated that the main vascular lesion in MMD is steno-occlusion of distal ICA caused by a fibrocellular intimal thickening with a multilayered elastic lamina and some lipid deposits [3], [7], [8], [9]. Despite there is an intimal proliferation, the media layer thickness is thinner [2], [10], and the smooth muscle cells undergo apoptosis [11].

Previous studies have revealed an abnormal expression of various angiogenesis-related genes and their products in MMD [2], [12], [13], [14], [15]. Of note, those studies mainly focused on a single or few interrelated genes or products at a time. Several studies reported that mutant $R N F 213$ mice could not recapitulate MMD pathology in vivo [16], [17]. In addition, the phenotype also could manifest as secondary to preexisting diseases [18], [19], [20], [21].

Hence, pathobiology of MMD might involve multiple pathways rather than single pathway. In this study, we collected tiny pieces of middle cerebral artery (MCA) walls from patients with MMD and analyzed global gene expression using RNA microarray to explore the novel mechanism of remodeling of the arterial walls in the MMD patients.

\section{Materials and Methods}

\section{Patients' population}

This study was performed under our institution guidelines provided by the ethics committee 
in our center as being described in our previous reports [3], [10], [11], [22]. Six patients underwent superficial temporal artery to MCA (STA-MCA) bypass procedures for the treatment of MMD at our center. In addition, we included two patients with large cerebral artery aneurysms that underwent bypass procedure as control. Clinical data of the patients were summarized in Table 1.

\section{Sample collection}

During STA-MCA bypass surgery, a 10 or 11-0 nylon monofilament was passed around the wall of the recipient artery. Then, vessel was pulled up by lifting the monofilament with forceps, and the operators (YT, SM) performed arteriotomy with micro-scissors (Figure 1). Then, collected tissues were rinsed with cold phosphate-buffered saline and immediately placed into RNAlater (Ambion, Austin, TX, USA) and stored at $-80^{\circ} \mathrm{C}$ until RNA extraction. The control specimens were obtained in a similar manner as being described in our previous reports [3], [10], [11], [22].

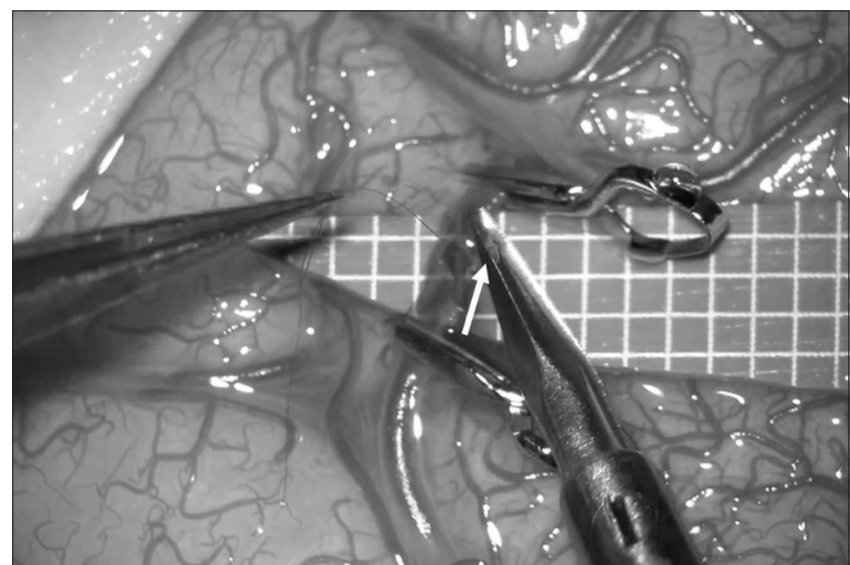

Figure 1: Intraoperative view of the specimen collection procedure. The vessel was pulled up by lifting the monofilament with forceps, and the arteriotomy was performed with micro-scissors. White arrow indicates tiny piece of artery for microarray analysis

\section{RNA preparation}

Total RNA was isolated separately from 6 MMD and 2 control MCA specimens using RNAqueous-Micro Kit (Ambion, Austin, TX, USA). The concentration and quality of RNA were determined using Agilent 2100 Bioanalyzer (Agilent Technologies, Inc., Wilmington, DE, USA). The extracted RNA was used for further procedures.

\section{Microarray analysis}

Microarray analysis was conducted by DNA Chip Research Inc. (Yokohama, Japan). RNA amplification was performed with Ovation ${ }^{\circledR}$ Pico-WTA (NuGEN Technologies, Inc., San Carlos, CA, USA). In brief, 500 pg of total RNA was reversely transcribed with random and oligo-dT primer. Then, the resultant firststrand complementary DNA (cDNA) was used to make the second strand. The purified CDNA was processed with SPIA ${ }^{\circledR}$ primer (NuGEN Technologies, San Carlos, CA, USA) and DNA polymerase to make a sufficient dose of cDNA. Purified cDNA was labeled with cyanin3, then hybridized to the Agilent Whole Human Genome DNA microarray 4x44K ver. 2.0 (Agilent Technologies, Inc., Wilmington, DE, USA). After washing, the microarray chip was scanned with DNA MicroArray Scanner (Agilent Tech.).

\section{Data analysis}

The data were digitalized with Feature Extraction ver. 9.5.3 (Agilent Technologies, Inc., Wilmington, DE, USA) as the manufacture's protocol. The digitalized data were imported into GeneSpring GX 11 (Agilent Technologies, Inc., Wilmington, DE, USA) and processed with the $75^{\text {th }}$ percentile shift and followed by quantile normalization. Normalization also performed among the genes with adjusted baseline to median of all sample. Each spot data were flagged in accordance with the feature and cut off if the feature is saturated, not uniform, population outlier, not positive, not significant, or not above background.

Analysis was performed using the base-2 logarithm transform of the normalized signal data with Office Excel 2010 (Microsoft, WA, USA). Welch's $t$-test was used to identify the differentially expressed genes in MMD compare to control, and $p<0.05$ was considered statistically significant. The genes were ranked according to their fold change and selected by criteria of fold change $>2.0$ for further pathway analysis with the online database PANTHER [23].

\section{Results}

As difficulty is expected, before the RNA preparation of these rare human surgical samples, we optimized our protocol of RNA extraction through

Table 1: Clinical features of 2 Control and 6 patients with MMD

\begin{tabular}{|c|c|c|c|c|c|}
\hline Age & Sex & Diagnosis & Onset symptom & Surgery & Concomitant vascular risk factors \\
\hline 60 & $\mathrm{~F}$ & Cerebral aneurysm & Incident & STA-MCA bypass \& clipping & HTN (-), Dyslipidemia (-), DM (-), Smoking (-) \\
\hline 52 & $\mathrm{~F}$ & Cerebral aneurysm & $\mathrm{SAH}$ & ECA-MCA bypass \& trapping & HTN (-), Dyslipidemia (-), DM (-), Smoking (-) \\
\hline 50 & $\mathrm{~F}$ & MMD & Adult/Ischemia & STA-MCA bypass & HTN (-), Dyslipidemia (-), DM (-), Smoking (-) \\
\hline 43 & M & MMD & Adult/Ischemia & STA-MCA bypass & HTN (-), Dyslipidemia (-), DM (-), Smoking (-) \\
\hline 31 & $\mathrm{~F}$ & MMD (Unilateral) & Adult/Ischemia & STA-MCA bypass & HTN (-), Dyslipidemia (-), DM (-), Smoking (-) \\
\hline 42 & $\mathrm{~F}$ & MMD (Unilateral) & Adult/Ischemia & STA-MCA bypass & HTN (-), Dyslipidemia (-), DM (-), Smoking (-) \\
\hline 44 & $\mathrm{~F}$ & MMD & Adult/Ischemia & STA-MCA bypass & HTN (-), Dyslipidemia (-), DM (-), Smoking (-) \\
\hline 41 & $\mathrm{~F}$ & MMD (Unilateral) & Adult/Ischemia & STA-MCA bypass & HTN (-), Dyslipidemia (-), DM (-), Smoking (-) \\
\hline
\end{tabular}


animal experimentation in mice. We found that the manufacture's protocol was effective for RNA extraction from a small piece of mice blood vessels. However, the quality of extracted RNA from surgical specimens was not entirely satisfactory, RNA integrity number below ideal value for microarray analysis $(r<7)$. We decided to accomplish the microarray as the screening work with the current available method.

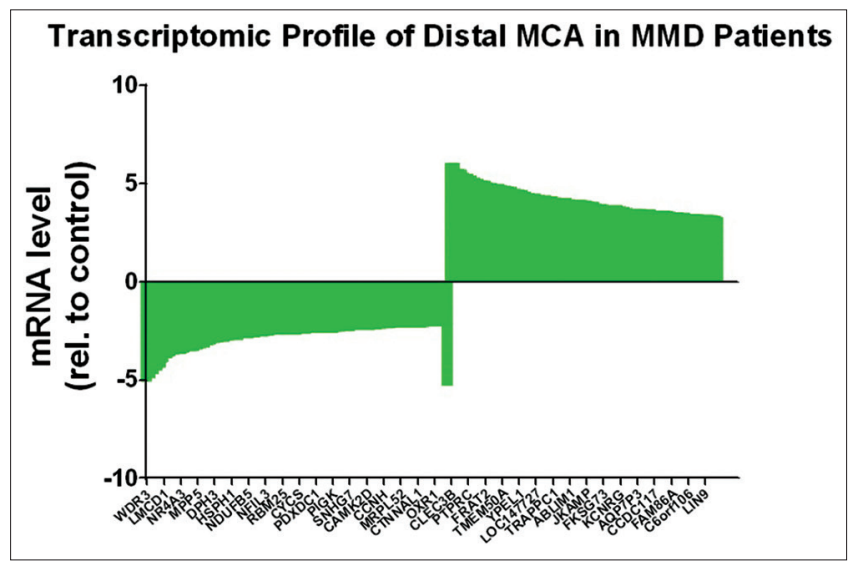

Figure 2: Normalized gene expression of distal MCA from MMD patients with $>2.0$ fold change. A total of 921 genes were distinctly regulated, 499 genes were up-regulated, and 422 genes were down-regulated

In this study, 42,405 gene probes remained after filtering for flags. Then, we selected the gene expression based on fold change $>2.0$ and $p<0.05$; as a result, 921 genes were found distinctly regulated between MCA of MMD and control. MCA of MMD was found to up-regulate 499 genes expression and downregulate 422 genes expression compare to control (Figure 2).

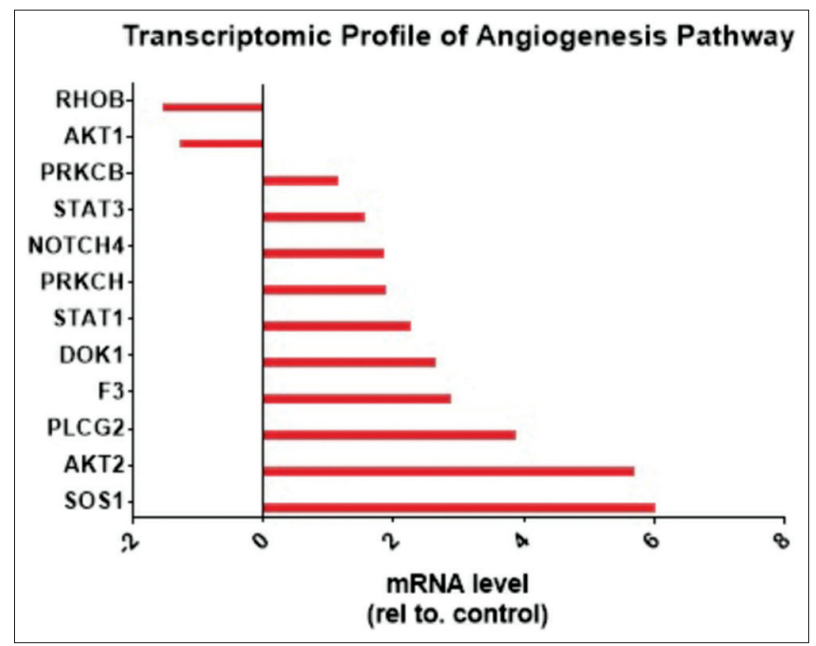

Figure 3: Normalized gene expression of distal MCA from MMD patients in angiogenesis pathway with $>2.0$ fold change. A total of 12 genes were distinctly regulated, 10 genes were up-regulated, and 2 genes were down-regulated

Among them, for example, sos1 (Fold change: 6.01 detected with each probe), AKT2 (5.71), OCLN (5.40), CD34 (4.38), HEY1 (3.68), ITGB2 (3.63), CLDN5 (3.40), SELP (2.86), NES (2.39), BAMBI (2.38), IL1B (2.31), STAT1 (2.27), APOE
(1.95), RB1 (1.94), ELN (1.93), NOTCH4 (1.86), ENG (1.48) and TLR4 (1.47) are up-regulated, and ACTN2 (2.72), IGFBP4 (2.61), SOX4 (2.27), DES (1.92), JunD (1.89), ETV6 (1.80), AKT1 (1.27), and XBP1 (1.09) are down-regulated. In this study, major angiogenic factors, such as vascular endothelial growth factor (VEGF), basic fibroblast growth factor (FGF), or RNF213, did not show a significant change in this study. On the other hand, Endoglin, previously reported as highly expressed in the endothelium of cerebral arterial wall of MMD patients, also up-regulated in this study.

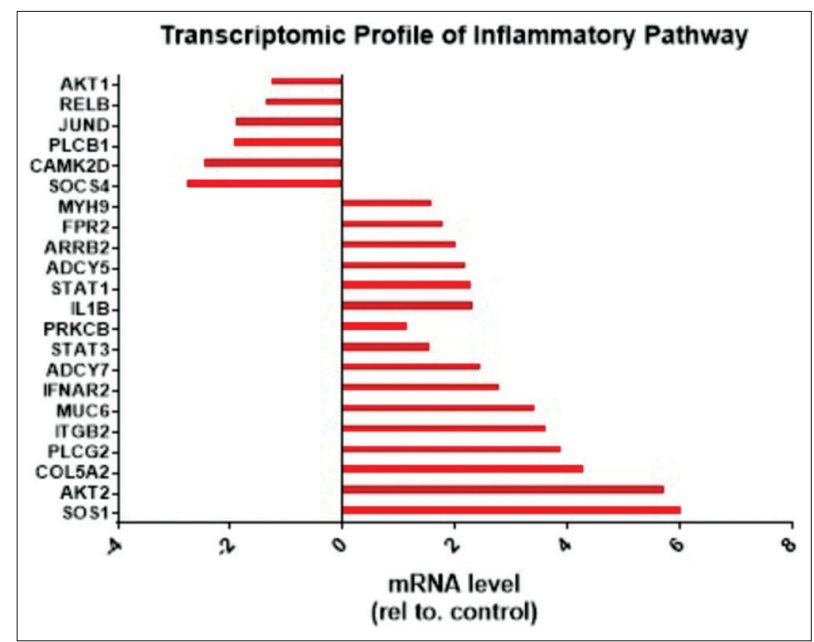

Figure 4: Normalized gene expression of distal MCA from MMD patients in inflammatory pathway with $>2.0$ fold change. A total of 22 genes were distinctly regulated, 16 genes were up-regulated and 6 genes were down-regulated

To investigate gene interaction, we clustered the gene probes according to signaling pathway with PANTHER database. In this study, at least five pathways were distinctly regulated in MMD: Angiogenesis (Figure 3), inflammation (Figure 4), integrin (Figure 5), WNT (Figure 6), and platelet-derived growth factor (PDGF) (Figure 7). SOS1 was shown to involve in all pathways, but WNT pathway. AKT2 was shown to involve in angiogenesis, inflammation, and PDGF pathway. Therefore, suggesting the importance of SOS1 and AKT2 in MMD.

\section{Discussion}

MMD is a steno-occlusive disease, primarily affects for brain vessels, or at least affects predominantly in cerebral arteries, and the etiology of this unique pathological condition remains elusive [1], [2], [24]. Recently, RNF213 was identified as a susceptibility gene for MMD. RNF213 is located in chromosome 17q25.3 and c.14576 G>A SNP increased the risk of having MMD, particularly in Asian population [4], [5], [6], [25]. 


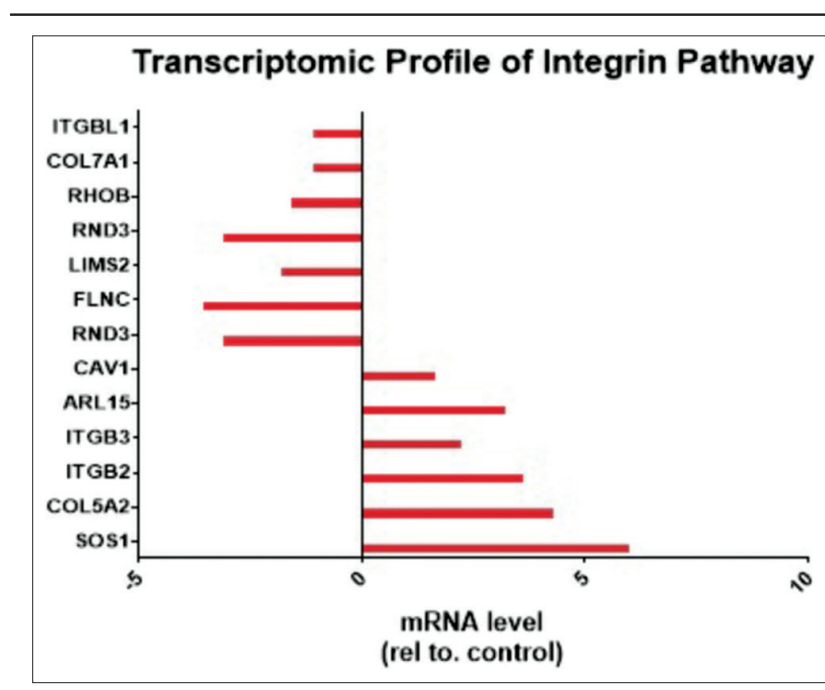

Figure 5: Normalized gene expression of distal MCA from MMD patients in integrin pathway with $>2.0$ fold change. A total of 13 genes were distinctly regulated, 6 genes were up-regulated, and 7 genes were down-regulated

Deletion of RNF213 in zebrafish results in abnormal sprouting of intracranial vessels and intersegmental arteries [4]. The over-expression of RNF213 in endothelial cells results in poor tube formation and decreased of proliferation rate [26]. However, mice with RNF213 mutation failed to recapitulate MMD phenotype [16], [17]. The pathology of MMD artery is characterized by intimal thickening with fibromuscular hyperplasia and media layer thinning, remains inexplicable through previous RNF213 studies. Hence, another approach is necessary to elucidate MMD pathobiology.

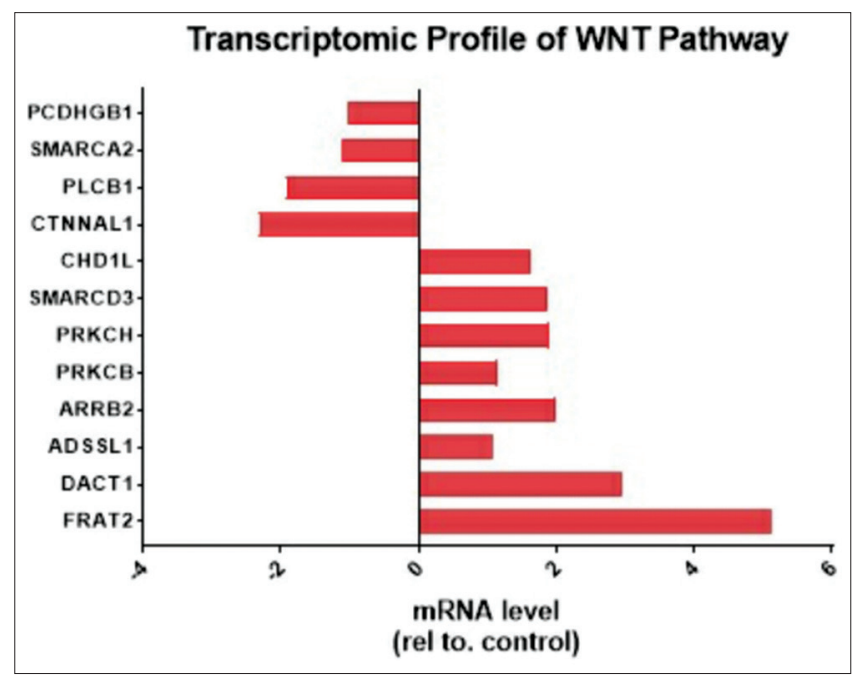

Figure 6: Normalized gene expression of distal MCA from MMD patients in WNT pathway with > 2.0 fold change. A total of 12 genes were distinctly regulated, 8 genes were up-regulated, and 4 genes were down-regulated

We previously reported that MMD pathology extends to distal MCA [11], [22], thus distal MCA may serve as valuable resource for MMD research. From our microarray study, we obtained that at least five pathways were distinctly regulated in distal MCA of patients with MMD: Angiogenesis, inflammation, integrin, PDGF, and WNT. From further analysis, AKT2 and SOS1 (son of sevenless homolog 1) were the most distinctly regulated genes compare to controls. Both AKT2 and SOS1 are related to RAS pathway that involves in multiple cellular processes, including proliferation, survival, and migration [27]. The RAS pathway is activated through integrin and growth factor signaling acts the controlling cellular machinery as a response to extracellular signal [27], [28].

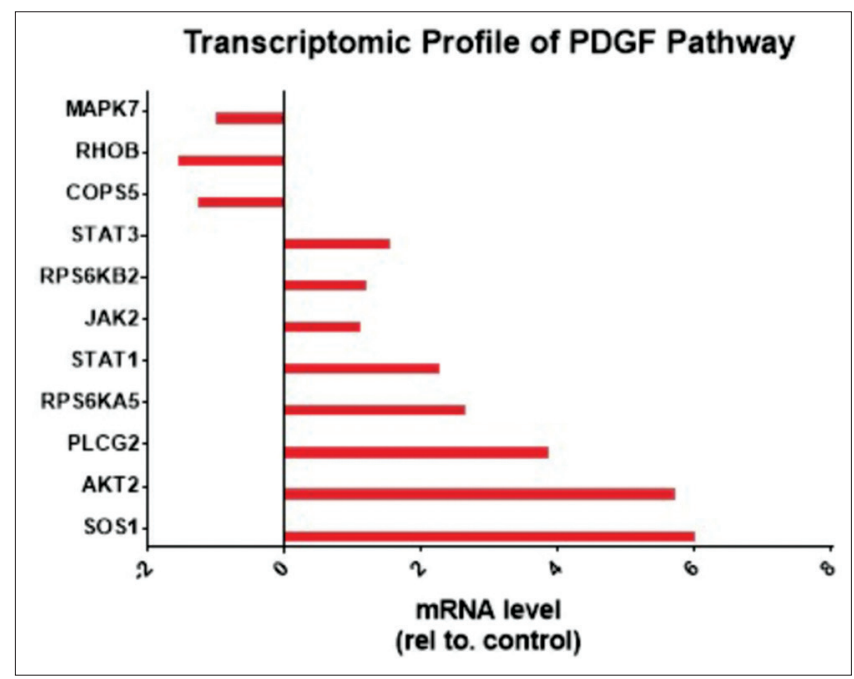

Figure 7: Normalized gene expression of distal MCA from MMD patients in PDGF pathway with $>2.0$ fold change. A total of 11 genes were distinctly regulated, 8 genes were up-regulated, and 3 genes were down-regulated

AKT2 is a member of the protein kinase $B$ family and acts as a downstream of RAS pathway, has been implicated in several cancer [28]. SOS1 is a member of guanosine nucleotide exchange factors that increases nucleotide exchange rate of GDP for GTP, resulting in RAS activation. Clinically related syndrome to SOS1 mutation is Noonan syndrome, a member of RASopathies [29]. Noonan syndrome is a congenital malformation characterized by variable congenital heart defects, short stature, skeletal malformations, and distinct facial anomalies [30]. In line with our results, moyamoya vasculopathy has been reported in patients with Noonan likedisorders [31], [32], [33], [34], [35], [36]. Moyamoya vasculopathy is also likely to occur in patients with other forms of RASopathies. Other forms of RASopathies: Cardiofaciocutaneous syndrome and Von Recklinghausen disease also reported to have a higher risk of having moyamoya vasculopathy [37], [38].

Nevertheless, our study has a major limitation due to the rarity of the specimens, we could not confirm the relevant gene expression on tissue samples. In this study, we also obtained a low RNA integrity number, suggesting some RNA has been degraded before extraction. RNA is susceptible for hydrolysis and rapidly degenerates, many manipulations and long duration for tissue harvesting, and probably the surgical field and tools were not RNAse free, all those factors may contribute to low RNA integrity number. We recommend for harvesting larger specimens and utilize RNAse free 
surgical tools to minimize enzymatic degradation of RNA.

Nevertheless, this investigation is useful as a biomolecular screening of abnormal pathways with the current available method. In line with our previous study, the distal MCA of patients with MMD involves in MMD pathology and has a distinct molecular expression in comparison to control distal MCA. In this study, RAS activation was observed in the distal MCA of patients with MMD, presumably contributes to intimal proliferation and stenosis of ICA, and thus plays a role in MMD pathology. Further investigation is needed to confirm the role of RAS pathway in MMD.

\section{Conclusions}

Through microarray analysis, we obtained that gene expression of distal MCA of patients with MMD was distinctly regulated in comparison with control. At least 5 pathways were altered in MMD: Angiogenesis, inflammation, integrin, PDGF, and WNT. Furthermore, SOS1 and AKT2 were the most altered genes in those aforementioned pathways. Nevertheless, our understanding about MMD pathobiology is still immature, further study is necessary.

\section{References}

1. Suzuki J, Takaku A. Cerebrovascular "moyamoya disease": A disease showing abnormal net-like vessels in base of brain. Arch Neurol. 1969;20(3):288-99. https://doi.org/10.1001/ archneur.1969.00480090076012

PMid:5775283

2. Suzui H, Hoshimaru M, Takahashi JA, Kikuchi H, Fukumoto M, Ohta $\mathrm{M}$, et al. Immunohistochemical reactions for fibroblast growth factor receptor in arteries of patients with moyamoya disease. Neurosurgery. 1994;35(1):20-5. https://doi. org/10.1097/00006123-199407000-00003

PMid:7936147

3. Takagi Y, Hermanto Y, Takahashi JC, Funaki T, Kikuchi T, Mineharu $Y$, et al. Histopathological characteristics of distal middle cerebral artery in adult and pediatric patients with moyamoya disease. Neurol Med Chir (Tokyo). 2016;56:345-9. https://doi.org/10.2176/nmc.oa.2016-0031

PMid:27087193

4. Liu W, Morito D, Takashima S, Mineharu Y, Kobayashi H, Hitomi T, et al. Identification of RNF213 as a susceptibility gene for moyamoya disease and its possible role in vascular development. PLoS One. 2011;6(7):e22542. https://doi. org/10.1371/journal.pone.0022542

PMid:21799892

5. Morimoto $\mathrm{T}$, Mineharu $\mathrm{Y}$, Kobayashi $\mathrm{H}$, Harada $\mathrm{KH}$, Funaki $\mathrm{T}$, Takagi Y, et al. Significant association of the RNF213 p.R4810K poly-morphism with Quasi-moyamoya disease. J Stroke Cerebrovasc Dis. 2016;25(11):2632-6. https://doi.org/10.1016/j. jstrokecerebrovasdis.2016.07.004

PMid:27476341

6. Akagawa H, Mukawa M, Nariai T, Nomura S, Aihara Y, Onda H, et al. Novel and recurrent RNF213 variants in Japanese pediatric patients with moyamoya disease. Hum Genome Var. 2018;5:17060. https://doi.org/10.1038/hgv.2017.60

7. Yamashita M, Oka K, Tanaka K. Histopathology of the brain vascular network in moyamoya disease. Stroke. 1983;14(1):508. https://doi.org/10.1161/01.str.14.1.50 PMid:6823686

8. Takebayashi S, Matsuo K, Kaneko M. Ultrastructural studies of cerebral arteries and collateral vessels in moyamoya disease. Stroke. 1984;15:728-32. https://doi.org/10.1161/01.str.15.4.728

9. Takekawa $\mathrm{Y}$, Umezawa $\mathrm{T}$, Ueno $\mathrm{Y}$, Sawada $\mathrm{T}$, Kobayashi M. Pathological and immunohistochemical findings of an autopsy case of adult moyamoya disease. Neuropathol. 2004;24(3):23642. https://doi.org/10.1111/j.1440-1789.2004.00550.x PMid:15484702

10. Takagi Y, Kikuta K, Nozaki K, Hashimoto N. Histological features of middle cerebral arteries from patients treated for moyamoya disease. Neurol Med Chir (Tokyo). 2007;47(1):1-4. https://doi. org/10.2176/nmc.47.1

PMid: 17245006

11. Takagi $Y$, Kikuta K, Sadamasa N, Nozaki K, Hashimoto N Caspase-3-dependent apoptosis in middle cerebral arteries in patients with moyamoya disease. Neurosurgery. 2006;59(4):894900. https://doi.org/10.1227/01.neu.0000232771.80339.15 PMid:17038954

12. Aoyagi $M$, Fukai $N$, Sakamoto $H$, Shinkai $T$, Matsushima $Y$, Yamamoto $\mathrm{M}$, et al. Altered cellular responses to serum mitogens, including platelet-derived growth factor, in cultured smooth muscle cells derived from arteries of patients with moyamoya disease. J Cell Physiol. 1991;147(2):191-8. https:// doi.org/10.1002/jcp.1041470202

PMid:2040653

13. Yoshimoto $\mathrm{T}$, Houkin $\mathrm{K}$, Takahashi A, Abe H. Angiogenic factors in moyamoya disease. Stroke. 1996;27:2160-5. https://doi. org/10.1161/01.str.27.12.2160

PMid:8969773

14. Hojo M, Hoshimaru M, Miyamoto S, Taki W, Nagata I, Asahi M, et al. Role of TGF- $\beta_{1}$ in the pathogenesis of moyamoya disease. J Neurosurg. 1998;89(4):623-9. https://doi.org/10.3171/ jns.1998.89.4.0623

PMid:9761057

15. Nanba R, Kuroda $S$, Ishikawa $T$, Houkin $K$, Iwasaki $Y$ Increased expression of hepatocyte growth factor in cerebrospinal fluid and intracranial artery in moyamoya disease. Stroke. 2004;35(12):2837-42. https://doi.org/10.1161/01. str.0000148237.13659.e6

PMid:15528455

16. Kanoke A, Fujimura M, Niizuma K, Ito A, Sakata H, Sato-Maeda M, et al. Temporal profile of the vascular anatomy evaluated by 9.4tesla magnetic resonance angiography and histological analysis in mice with R4859K mutation of RNF213, the susceptibility gene for moyamoya disease. Brain Res. 2015;1624:497-505. https://doi.org/10.1016/j.brainres.2015.07.039 PMid:26315378

17. Kobayashi $H$, Matsuda $Y$, Hitomi $T$, Okuda $H$, Shioi $H$ Matsuda $\mathrm{T}$, et al. Biochemical and functional characterization of RNF213 (Mysterin) R4810K, a susceptibility mutation of moyamoya disease, in angiongenesis in vitro and in vivo. J Am Heart Assoc. 2015;4(7):e002146. https://doi.org/10.1016/j. brainres.2015.07.039

PMid:26126547

18. Koss $M$, Scott RM, Irons MB, Smith ER, Ullrich NJ 
Moyamoya syndrome associated with neurofibromatosis Type 1: Perioperative and long-term outcome after surgical revascularization. J Neurosurg Pediatr. 2013;11(4):417-25. https://doi.org/10.3171/2012.12.peds12281

PMid:23373626

19. Hyakuna N, Muramatsu H, Higa T, Chinen Y, Wang X, Kojima S. Germline mutation of CBL is associated with MMD in a child with juvenile myelomonocytic leukemia and noonan syndrome-like disorder. Pediatr Blood Cancer. 2015;62(3):542-44. https://doi. org/10.1002/pbc.25271

PMid:25283271

20. Lo FS, Wang CJ, Wong MC, Lee NC. Moyamoya disease in two patients with Noonan-like syndrome with loose anagen hair. Am J Med Genet A. 2015;167(6):1285-8. https://doi.org/10.1002/ ajmg.a.37053 PMid:25858597

21. See AP, Ropper AE, Underberg DL, Robertson RL, Scott RM, Smith ER. Down syndrome and moyamoya: Clinical presentation and surgical management. J Neursurg Pediatr. 2015;16(1):5863. https://doi.org/10.3171/2014.12.peds 14563 PMid:25837890

22. Takagi $\mathrm{Y}$, Kikuta $\mathrm{KI}$, Nozaki $\mathrm{K}$, Fujimoto $\mathrm{M}$, Hayashi J, Imamura $\mathrm{H}$, et al. Expression of hypoxia-inducing factor-10 and endoglin in intimal hyperplasia of the middle cerebral artery of patients with moyamoya disease. Neurosurgery. 2007;60(2):338-45; discussion 345. https://doi.org/10.1227/01. neu.0000249275.87310.ff

PMid:17290185

23. Thomas PD, Campbell MJ, Kejariwal A, Mi H, Karlak B, Daverman R, et al. PANTHER: A library of protein families and sub-families indexed by function. Genome Res. 2003;13(9):2129-41. https://doi.org/10.1101/gr.772403 PMid:12952881

24. Suzuki J, Kodama N. Moyamoya disease a review. Stroke. 1989;14(1):104-9. PMid:6823678

25. Miyawaki S, Imai $\mathrm{H}$, Shimizu $\mathrm{M}$, Yagi $\mathrm{S}$, Ono $\mathrm{H}$, Mukasa $\mathrm{A}$, et al. Genetic variant RNF213 c.14576G $>A$ in various phenotypes of intracranial major artery stenosis/occlusion. Stroke. 2013;44(10):2894-7. https://doi.org/10.1161/ strokeaha.113.002477 PMid:23970789

26. Hitomi T, Habu T, Kobayashi H, Okuda H, Harada KH, Osafune K, et al. Down- regulation of securin by the variant RNF213 R4810K (rs112735431, G>A) reduces angiogenic activity of induced pluripotent stem cell-derived vascular endothelial cells from moyamoya patients. Biochem Biophys Res Commun. 2013;438(1):13-9. https://doi.org/10.1016/j.bbrc.2013.07.004 PMid:23850618

27. Guo W, Giancotti FG. Integrin signaling during tumour progression. Nat Rev Mol Cell Biol. 2004;5(10):816-26. https:// doi.org/10.1038/nrm1490

\section{PMid: 15459662}

28. Liu A, Testa JR, Hamilton TC, Jove R, Nicosia SV, Cheng JQ. AKT2, a member of the protein kinase $B$ family, is activated by growth factors, v-Ha-ras, and v-src through phosphatidylinositol 3-kinase in human ovarian epithelial cancer cells. Cancer Res. 1998;58(14):2973-7.

\section{PMid:9679957}

29. Roberts AE, Araki T, Swanson KD, Montgomery KT, Schiripo TA Joshi VA, et al. Germline gain-of-function mutations in SOS1 cause Noonan syndrome. Nat Genet. 2007:39(1):70-4. https:// doi.org/10.1038/ng1926

PMid: 17143285

30. Tartaglia M, Kalidas K, Shaw A, Song X, Musat DL, van der Burgt, et al. PTPN11 mutations in Noonan syndrome: Molecular spectrum, genotype-phenotype correlation, and phenotypic heterogeneity. Am J Hum Genet. 2003;70:1555-63. https://doi. org/10.1086/340847

PMid:11992261

31. Ganesan V, Kirkham FJ. Noonan syndrome and moyamoya. Pediatr Neurol. 1997;16(3):256-8.

PMid:9165521

32. Schuster JM, Roberts TS. Symptomatic moyamoya disease and aortic coarctation in a patient with Noonan's syndrome: Strategies for management. Pediatr Neurosurg. 1999;30(4):206-10. PMid: 10420132

33. Tang KT, Yang W, Wong J, Lee KY. Noonan syndrome associated with moyamoya disease: Report of one case. Acta Pediatr Taiwan. 1999;40(4):274-6.

PMid:10910629

34. Yamashita Y, Kusaga A, Koga Y, Nagamitsu S, Matsuishi T. Noonan syndrome, moyamoya-like vascular changes and antiphospholipid syndrome. Pediatr Neurol. 2004;31(5):364-6. https://doi.org/10.1016/j.pediatrneurol.2004.05.015

PMid:15519121

35. Hung PC, Wang HS, Wong AM. Moyamoya syndrome in a child with Noonan syndrome. Pediatr Neurol. 2011;45(2):129-31. PMid:21763956

36. Choi JH, Oh MY, Yum MS, Lee BH, Kim GH, Yoo HW. Moyamoya syndrome in a patient with Noonan-like syndrome with loose anagen hair. Pediatr Neurol. 2015;52(3):352-5. https://doi. org/10.1016/j.pediatrneurol.2014.11.017 PMid:25563136

37. Hayashi K, Morofuji $\mathrm{Y}$, Horie N, Izumo T. A case of neurofibromatosis type 1 complicated with repeated intracerebral hemorrhage due to quasi-moyamoya disease. J Stroke Cerebrovasc Dis. 2015;24(5):e109-13. https://doi. org/10.1016/j.jstrokecerebrovasdis.2014.12.029

38. Ishiguro Y, Kubota T, Takenaka J, Maruyama K, Okumura A, Negoro $\mathrm{T}$, et al. Cardio-facio-cutaneous syndrome and moyamoya syndrome. Brain Dev. 2002;24(4):245-9. https://doi. org/10.1016/s0387-7604(02)00014-1

PMid:12015168 